San Jose State University

SJSU ScholarWorks

Master's Theses

Master's Theses and Graduate Research

Fall 2009

\title{
Host majority group members' acculturation attitudes towards immigrant groups.
}

Kanako Miwa

San Jose State University

Follow this and additional works at: https://scholarworks.sjsu.edu/etd_theses

\section{Recommended Citation}

Miwa, Kanako, "Host majority group members' acculturation attitudes towards immigrant groups." (2009). Master's Theses. 4011.

DOI: https://doi.org/10.31979/etd.8tas-drff

https://scholarworks.sjsu.edu/etd_theses/4011

This Thesis is brought to you for free and open access by the Master's Theses and Graduate Research at SJSU ScholarWorks. It has been accepted for inclusion in Master's Theses by an authorized administrator of SJSU ScholarWorks. For more information, please contact scholarworks@sjsu.edu. 


\author{
A Thesis \\ Presented to \\ The Faculty of the Department of Psychology
}

San Jose State University

In Partial Fulfillment

of the Requirements for the Degree

Master of Science

by

Kanako Miwa

December 2009 
UMI Number: 1484369

All rights reserved

INFORMATION TO ALL USERS

The quality of this reproduction is dependent upon the quality of the copy submitted.

In the unlikely event that the author did not send a complete manuscript and there are missing pages, these will be noted. Also, if material had to be removed, a note will indicate the deletion.

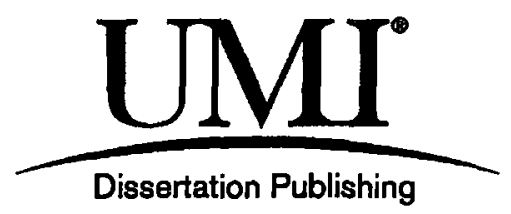

UMI 1484369

Copyright 2010 by ProQuest LLC.

All rights reserved. This edition of the work is protected against unauthorized copying under Title 17, United States Code.

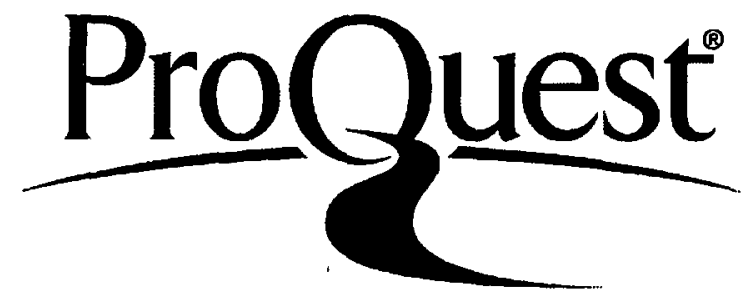

ProQuest LLC

789 East Eisenhower Parkway

P.O. Box 1346

Ann Arbor, Ml 48106-1346 
(C) 2009

Kanako Miwa

ALL RIGHTS RESERVED 
SAN JOSE STATE UNIVERSITY

The Undersigned Thesis Committee Approves the Thesis Titled

HOST MAJORITY GROUP MEMBERS' ACCULTURATION ATTITUDES TOWARDS IMMIGRANT GROUPS

By

Kanako Miwa

APPROVED FOR THE DEPARTMENT OF PSYCHOLOGY
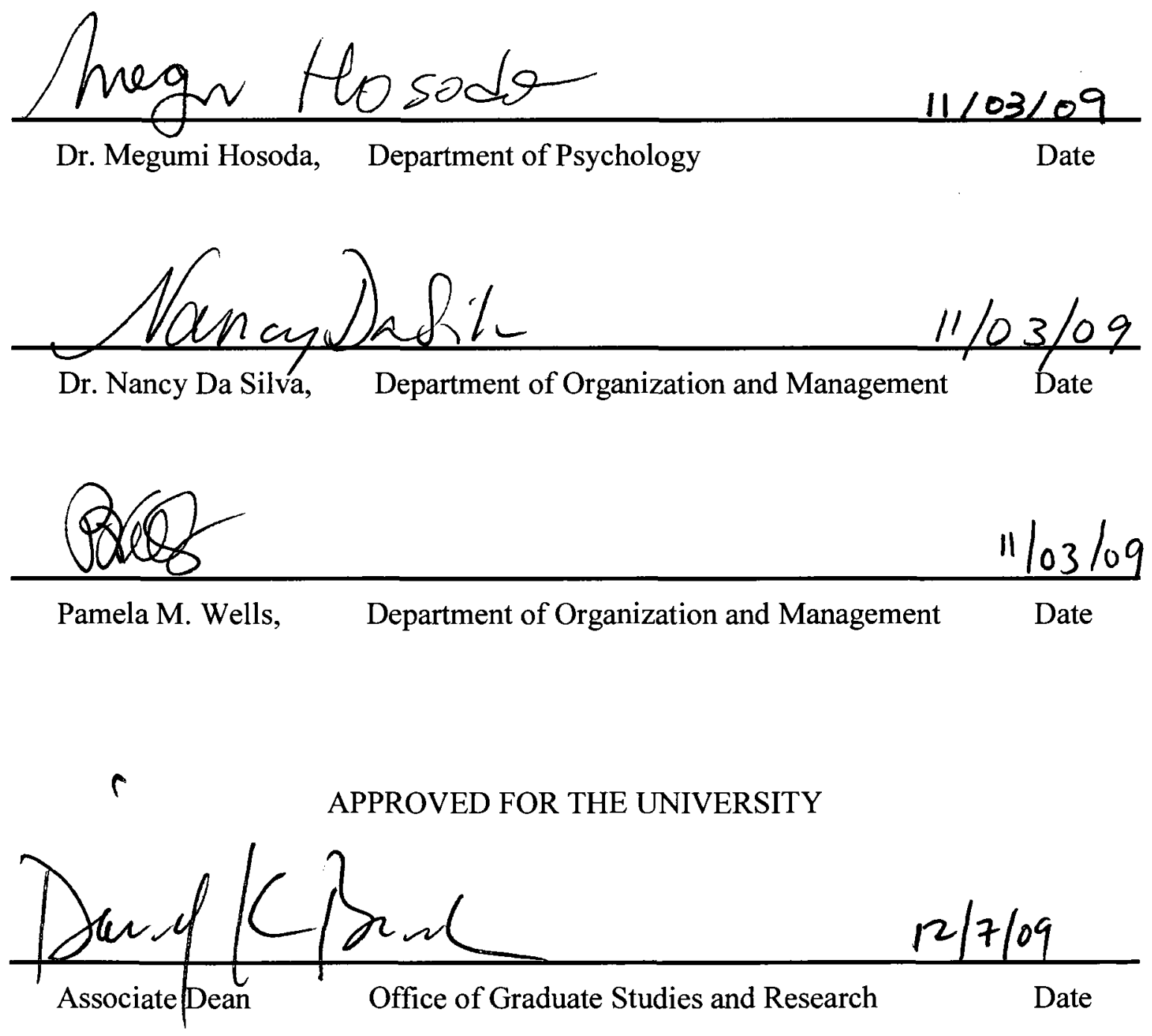


\section{ABSTRACT \\ HOST MAJORITY GROUP MEMBERS' ACCULTURATION ATTITUDES TOWARDS IMMIGRANT GROUPS \\ By Kanako Miwa}

One out of every four individuals residing in the U.S. lived in another country before moving to the U.S. Such an individual has to face acculturation. Research has consistently shown that immigrants differ in how they go about their acculturation. However, little is known about what acculturation strategies the majority group members believe immigrants should adopt in the host country. Therefore, the present study examines the host majority group members' (Euro-Americans) acculturation orientations toward two immigrant groups (Mexican and Japanese) on different life domains and identifies individual difference factors (e.g., social dominance orientation, social distance, and self-efficacy) that are related to each of the acculturation strategies differently. Data were collected from 128 respondents of Euro-American college students in the SF Bay Area, California. Results indicated that integrationism and individualism were the most preferred acculturation orientations endorsed by Euro-Americans towards both immigrant groups for both life domains. In contrast, exclusionism was the least preferred acculturation orientation followed by segregationism. In addition, the immigrant groups' country of origin (either Mexico or Japan) did not have a significant effect on the acculturation orientations endorsed by host majority group members. Social dominance orientation and social distance were significant determinants of each acculturation orientation. 


\section{ACKNOWLEDGEMENTS}

This thesis would not have been possible without the help of many people. First and foremost, I would like to show my gratitude to Dr. Megumi Hosoda, my adviser. She has supported me from the initial to the final level with her patience, friendliness, and knowledge while she has also taught me to be a better thinker and researcher. I would like to thank her for teaching, listening, challenging, chatting, and laughing with me. Most importantly, she has helped me to deal with difficulties in my life and helped me to become a better person. One simply could not wish for a better, friendlier, and more considerate adviser.

I am whole heartily thankful to Dr. Nancy Da Silva whose guidance and support enabled me to develop an understanding of statistics and research methodology. She has made my thesis better with her knowledge, understanding and, insight. Her enthusiasm about research methodology, statistics, and scale development has influenced my life as I have pursued my career into the analytic field of research.

I would also like to thank to Pamela Wells for being part of my thesis committee and for her guidance and encouragement. Her positive personality and lively character have always provided me an incentive to work harder on my thesis even when I faced difficulties.

I thank my family for being a pillar of support and their encouragement. I thank my parents for continuously making sacrifices so that I can pursue my education in the United States. 
I thank Mayuko Onuki, my best friend, co-researcher, and a partner in crime, for always being there for me. I thank her for staying up all night listening to my ideas and problems, talking about cultural psychology, and helping me with statistical analysis. The uncountable overnight virtual parties over the phone made my thesis possible. I truly appreciate her help, company, humor, and knowledge. My life would have been different without knowing her.

I owe my deepest gratitude to my husband, Paul, for being patient, understandable, and thoughtful. I thank him for listening to my complaints, supporting me emotionally, laughing with me, and making me smile during the writing of my thesis. Words don't begin to express my gratitude. I could have never undertaken this venture and successfully completed it if not for him.

Lastly, I offer my regards and blessings to all of those who supported me in any respect during the completion of my thesis. 


\section{TABLE OF CONTENTS}

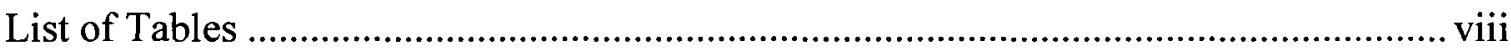

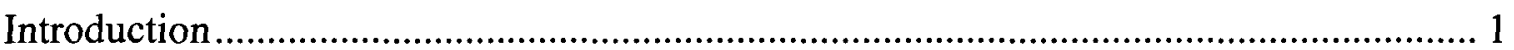

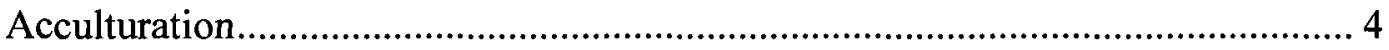

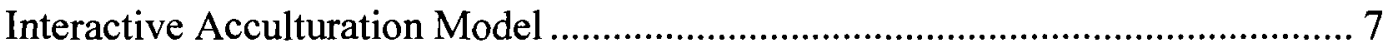

Individual Difference Factors ............................................................................ 16

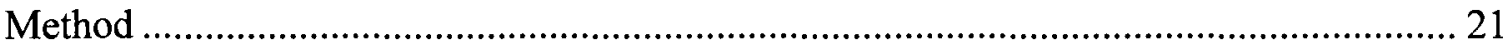

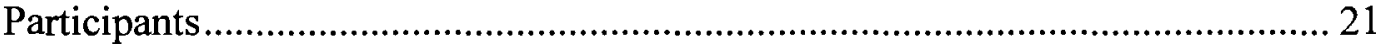

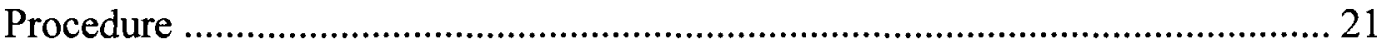

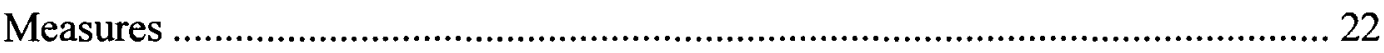

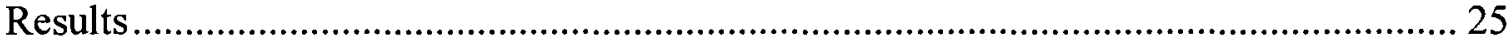

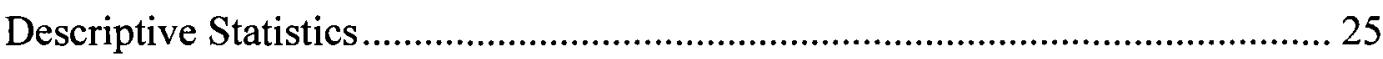

Test of Hypotheses................................................................................................ 30

Test of Research Question ................................................................................. 32

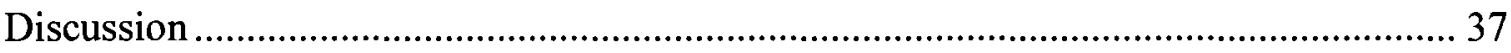

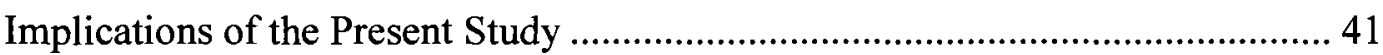

Limitations and Directions for Future Research ................................................ 44

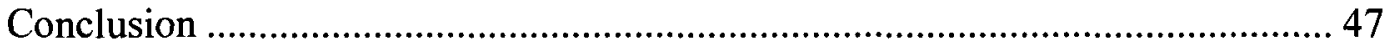

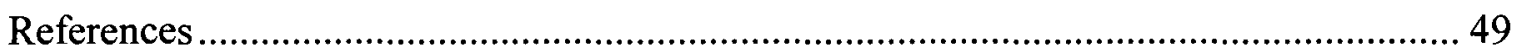

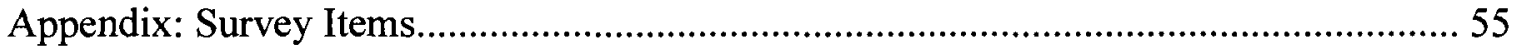




\section{LIST OF TABLES}

Table 1. Means and Standard Deviations as a Function of the National

Origin of Immigrant Groups and Life Domains

Table 2. Means, Standard Deviations, Correlations, and Internal Consistency

Reliabilities of the Measured Variable.

Table 3. Summary Statistics for Multiple Regression Analysis on Acculturation

Orientations (Public Domain).

Table 4. Summary statistics for Multiple Regression Analysis on Acculturation Orientations (Private Domain) 


\section{Introduction}

The United States is a country that has a long history of accepting immigrants. According to the U.S. Citizenship and Immigration Services (2007), 37.9 million foreignborn individuals live in the U.S., representing about $12.5 \%$ of the entire population. When these individuals immigrate to the United States, they are often exposed to new culture, values, food, and customs, and are in need of adjusting to the new environment.

Thus, one of the major issues in research on immigrants and immigration is to understand how immigrants change and adapt to a new cultural context (Berry, 1990). Although much research attention has focused on the examination of the acculturation strategies of immigrants, and its antecedents and consequences, previous acculturation research has neglected to examine host majority group members' orientations towards immigrants' acculturation strategies, that is, the perceptions of majority/dominant group members on how immigrants should adapt to the dominant culture within the host country (e.g., Bourhis \& Dayan, 2004). This line of research is important because the dominant group of society plays a powerful role in shaping immigrants' acculturation strategies (Berry, 2003). More specifically, it is the attitudes of these members that form the societal, immigration, and organizational policies that might inadvertently affect

immigrants (e.g., discrimination, exclusion, negative stereotype) (Eseses, Dovidio, Jackson, \& Armstrong, 2001). For example, dominant group members might prevent immigrant groups from fully participating in society if they possess negative stereotypes towards these immigrant groups or if they consider these immigrant groups' economic and social status within the host country to be adverse to the dominant group members 
(e.g., Bourhis, Moise, Perreault, \& Senecal, 1997; Stephan, Ybarra \& Bachman et al., 1999). Sayegh and Lasry (1993), after reviewing literature on acculturation, asserted that immigrants preferred to maintain their heritage cultures, but at the same time, they were concerned about interacting with host ethnic group members. Thus, potential obstacles to the social interactions of immigrants with host majority group members need to be understood by studying the attitudes and the interaction between members of both immigrant and host groups. Therefore, more recent research on acculturation has focused on the examination of how contact between dominant and non-dominant group members influences each other's perception, inter-group attitudes or behavior as a function of the non-dominant groups' countries of origins and their perceived status within the host countries (Berry, 1997; Bourhis et al., 1997).

In addition, researchers (e.g., Arends-Toth \& Van de Vijver, 2004) have argued that acculturation strategies that dominant group members prefer might differ depending on specific life domains (i.e., public and private). For example, Turkish-Dutch immigrants preferred to adopt dominant Dutch culture in public settings, but they preferred to maintain their heritage culture and not to adopt Dutch culture in private settings. On the other hand, Dutch majority individuals preferred Turkish-Dutch immigrants to adopt the dominant Dutch culture in all life domains (Arends-Toth \& Van de Vijver, 2003). These findings suggest that minority and majority group members' attitudes towards acculturation differ in specific life domains, and indicate that it is necessary to further understand the phenomena of both immigrants' acculturation 
strategies as well as the perception of majority groups' acculturation strategies towards immigrant groups in different life domains.

Understanding what strategies majority group members prefer immigrants to adopt within the host country is important. This is especially true in the workplace, because majority members' preferred acculturative expectations in the workplace might result in negative outcomes for many immigrant workers (e.g., English only policy in the workplace, prohibition of religious observances) or prevent them from reaching their potential (e.g., denial of promotion).

More recent research has also investigated how individual as well as intergroup relations variables are related to acculturation orientations. For example, Bourhis and Dayan (2004) examined the relationship between Jewish undergraduate students' attitudes towards two immigrant groups (Jewish and Israeli Arabs), and intergroup variables. Results showed that students who endorsed welcoming attitudes towards immigrants were likely to seek casual and personal relationship with them, were likely to have greater tolerance of ethnic diversity, and were less likely to prefer inequality within social group relationships. On the contrary, students who expressed unwelcoming attitudes towards immigrants were unwilling to have personal or even casual relations with them, were likely to support group inequality, and were not very tolerant of ethnic diversity. Acculturation is a product of a relational outcome between immigrants and the majority group (Bourhis et al., 1997). Thus, it is important to examine how individual and intergroup variables are associated with majority group's acculturation attitudes. 
Therefore, the major purposes of this study are twofold; it examines dominant group members' (i.e., European American) acculturation orientations towards specific immigrant groups (i.e., Mexican and Japanese) in the United States as a function of life domains and investigates how psychological profiles of dominant group members are related to various acculturation strategies. More specifically, this study examines how dominant members' intergroup attitudes (i.e., social dominance orientation, and ethnic proximity) and self-concepts (i.e., self-efficacy) are related to different acculturation strategies towards these two immigrant groups.

The following sections summarize the research on immigrants' acculturation strategies and dominant groups' acculturation expectations, followed by the dominant group members' endorsement of acculturation orientations and their social psychological profiles in relation to each of the acculturation strategies. Hypotheses that are tested are presented.

\section{Acculturation}

\section{Definition}

The early interest in acculturation began in the anthropological and sociological communities, and the term acculturation was initially defined as "those phenomena which result when groups of individuals having different cultures come into continuous firsthand contact with subsequent changes in the original culture patterns of either or both groups" (Redfield, Linton \& Herskovits, 1936, p. 149). Acculturation takes place at two levels: individual and group (Berry, 2003). Although many disciplines such as anthropology, sociology, economics, and political science have been studying 
acculturation at the group level, Graves (1967) is probably the first person who suggested the distinction between the group level and the individual level acculturation. He refers to the individual level of acculturation as "psychological acculturation" and defines it as the process by which individuals change and adapt to the cultural context in which they live as a result of being in contact with other cultures, whereas group level acculturation is defined as a broader concept of a change within the culture itself which results in population-level changes that are due to contact with other cultures (Berry, Kim, \& Boski, 1988). Group acculturation usually takes time as an ecological change in adjustment is not a rapid process, whereas individual acculturation is a more direct change in individuals from the contact of the other culture. According to Berry (2001), when immigrating individuals are the target to be examined, it is at the individual level of acculturation, and when groups or a larger population in a society are examined, it is referred to as a group level acculturation.

\section{Dimensionality and Strategies}

Acculturation was originally thought of as a linear or unidimensional process (Graves, 1967), with individuals moving from one pole (e.g., maintaining one's own heritage culture) to another (e.g., assimilating host culture). This model implies a bipolar continuum, which means that the degree of losing heritage culture reflects the degree of amalgamating into host culture, or maintaining one's heritage culture reflects the degree of separating oneself from the host culture.

However, more recently, Berry (1990) proposed a bidimensional model of acculturation. He suggested that one's orientation to his/her heritage culture and to a host 
culture could be considered as independent dimensions rather than as the opposite ends of a single continuum. In this model, immigrants have to deal with two central issues when they acculturate: (a) the extent to which they wish to maintain their own ethnic/cultural identity and (b) the extent to which they are motivated to identity with the mainstream, dominant culture. Consequently, the negotiation of these two central issues results in four distinct acculturation strategies: integration (identification with both cultures), assimilation (identification mostly with the dominant culture), separation (identification mostly with one's own heritage culture), or marginalization (low identification with both cultures). To illustrate, integrated immigrants (e.g., Asian, Latin American) living in the U.S. would identify themselves with their own heritage cultures (e.g., Asian, Latin American) as well as the mainstream American culture. Conversely, immigrants who do not want to maintain their own heritage culture and identity, but seek to have contact with American culture, are using the assimilation strategy. Those immigrants who seek to maintain their own heritage culture, but do not have an intention to have contact with American culture, are endorsing the separation strategy. Finally, when immigrants have no preference for maintaining their heritage culture or adapting to American culture, they are using the marginalization strategy. Numerous empirical studies have shown that integration is the most preferred strategy, followed by assimilation and separation, and that marginalization is the least preferred choice of strategy among immigrants across many different ethnic groups (e.g., Berry, Kim, Power, Young, \& Bujaki, 1989; Berry \& Krishnan, 1992; Dona, \& Berry, 1994; Van Oudenhoven, Prins, \& Buunk, 1998). 
According to Berry et al. (1989), acculturation requires contact between at least two independent cultural groups, resulting in changes in one or both of the groups. However, in reality, one group usually dominates and contributes more to the flow of cultural elements than does the other group (i.e., non-dominant group). Therefore, Berry (2003) has argued that the dominant group plays a powerful role in the acculturation process of immigrants. This is particularly important when the dominant group "enforces certain forms of acculturation or constraints on the choices of non-dominant groups or individuals," such as the case of the "melting pot" culture of the United States (Berry, 2003, p. 23). These acculturation expectations play an important role in multicultural ideology for both dominant and non-dominant groups. For non-dominant groups, the concern is how "we" should adapt to "their" culture, whereas for dominant groups, primary attention is how "they" should adapt to "our" culture. Indeed, the choices of acculturation strategies that non-dominant groups make are influenced by how they perceive the acculturation expectations of dominant groups towards them (Bourhis et al., 1997). Therefore, both dominant and non-dominant groups are involved in the process of successful multiculturalism for the larger society.

\section{Interactive Acculturation Model}

Researchers have expanded theories, models, and typologies of acculturation based on Berry's (1990) bidimensional model mentioned above (e.g., LaFromboise, Coleman, \& Gerton 1993; Rudmin \& Ahmadzadeh, 2001; Padilla, \& Perez, 2003; Navas, Garcia, Sanchez, Rojas, Pumares, \& Fernandez, 2005). Among them, Bourhis and his colleagues (Bourhis et al., 1997) developed an interactive acculturation model (IAM) by 
incorporating dominant group members' expected acculturation orientations towards nondominant group members, and asserted that the dominant group members' expected acculturation orientations would influence the type of acculturation strategies that nondominant group members adopt. The IAM is the first acculturation model which emphasizes the influence of dominant group members' expected acculturation orientations towards immigrant groups.

Acculturation Strategies

As in the case of Berry's acculturation model, from the dominant group members' point of views, IAM deals with two issues: (1) "Do you find it acceptable that immigrants maintain their cultural heritage?"' and (2) "Do you accept that immigrants adopt the culture of your host community?" (Bourhis et al., 1997, p.380). Responses to these two dimensions result in the five different acculturation strategies that dominant group members prefer for immigrants to adopt: integrationism, individualism, assimilationism, segregationism, and exclusionism. Integrationism is defined as that "host community members accept and value the maintenance of the heritage culture of immigrants and also accept that immigrants adopt important features of the majority host culture" (p.380). Individualism is an orientation in which "host community members define themselves and others as individuals rather than as members of group categories such as immigrants or host community members" (p. 381). Those who adopt the individualist orientation do not distinguish themselves and others as group members, but rather they perceive and treat every individual as being equal, regardless of their ethnicity or social status. Assimilationism occurs when "host community members expect immigrants to relinquish 
their cultural identity for the sake of adopting the culture of the majority host society" (p.380). Members of the host community who prefer segregationism "distance themselves from immigrants by not wishing them to adopt or transform the host culture, but they accept that immigrants maintain their heritage culture" (p 380). Finally, exclusionism is defined as the "members of host community are not only intolerant of the maintenance of the immigrant culture but also refuse to allow immigrants to adopt features of the host culture" (p. 381). Therefore, integrationism and individualism are considered as welcoming attitudes of dominant group members towards immigrants, whereas assimilationism, segregationism, and exclusionism are considered to be unwelcoming/rejecting attitudes of immigrants or their cultural values by the dominant group members (Montreuil \& Bourhis, 2004).

One unique aspect of this model over other acculturation models is an inclusion of individualism as a culture free orientation. The notion of this orientation originated from the most popular cultural value system: individualism and collectivism (Bourhis et al., 1997). Individualists view themselves as being independent of collectives, whereas collectivists see themselves as part of a collective entity (Triandis, 1975). Therefore, individualists tend to reject being categorized, and perceive others and themselves as an individual person, not as a member of a group. When these individuals respond negatively to the two domains (acceptance of maintenance of immigrants' heritage culture in the host country and acceptance of immigrants' adaptation of the dominant culture) they do so not because they prefer to marginalize immigrants, but because they 
identify others as an individual, regardless of their national origins. Theoretically, this model differentiates individualism from exclusionism.

Target Group Specificity

Another contribution of the IAM is its flexibility to examine host dominant group members' orientations towards any "specific" non-dominant groups (e.g., language usage, race, ethnicity) on the basis of the inter-group context which is relevant to a particular host society. The model also suggests that dominant group members' acculturation orientations towards non-dominant group members might differ as a function of the national origin of the non-dominant group members. There is empirical support for the different acculturation expectations of dominant group members as a function of specific non-dominant group members.

Montreuil and Bourhis (2004) examined dominant group members' acculturation orientations towards "valued" and "devalued" immigrants in Canada. Generally, "valued" immigrant groups are types of immigrants who are perceived as favorable by members of the host majority in the country of settlement and are the target of positive stereotypes. Valued immigrants are seen to benefit the local economy, or share a common language or culture with the host society. Conversely, "devalued" immigrant groups are usually perceived unfavorably by host majority members and are the target of negative stereotypes. Devalued immigrants are seen as economic rivals for employment and housing, or a drain on the welfare structure of the country of settlement (Montreuil \& Bourhis, 2001). 
Bourhis and Montreuil (2004) reported that Quebec Francophones endorsed integrationism and individualism towards "valued" immigrants (i.e., French immigrants), but assimilation, segregation, and exclusion strategies towards the "devalued" immigrants. Similarly, Bourhis and Dayan (2004) examined host dominant Jewish members' acculturation orientations towards valued (i.e., Jewish-Russian and Ethiopian immigrants) and devalued (i.e., Israeli Arabs) immigrant groups in Israel. Results showed that dominant Jewish members preferred integrationism and individualism towards the valued immigrants, but that segregationist and exclusionist orientations were the most preferred orientations towards the devalued immigrants. These results show that host majority members' acculturation expectations indeed differ depending on the valued or devalued status of immigrants being considered and that acculturation orientations towards members of the devalued groups are distinctively less favorable than is the case for the valued groups. Such differential orientations might influence how members of these two groups are treated in the society (è.g., job opportunities, economic status).

Thus, given the above findings as well as the negative connotation often associated with a term "immigrants in general" (Esses, Dovidio, Jackson \& Armstrong, 2001 ), it is important to study majority group members' acculturation expectations towards specific immigrant groups rather than towards immigrants in general because immigrants in general might evoke subjective representations of more "problematic" immigrant groups or have "carry over" effects from the mass media associating specific immigrant groups with disputable incidents and events (Esses et al., 2001). 


\section{Valued and Devalued Groups in the United States}

In pluralistic societies, not all of ethnic immigrant groups are equally welcome to the host countries; some immigrant groups possess higher prestige and status and other immigrant groups possess lower prestige and status in the host country because of dominant group members' prejudice against certain immigrant groups on the basis of ethnicity, race, or religion (Berry, 2001).

In the United States, much of intergroup relations research has focused on the relationship between European Americans and African Americans (e.g., DuBors \& Hirsch, 1990; Steffensmeier \& Ulmer, 2006; Doyle, Beaudet, \& Aboud, 1988). However, because of the burgeoning number of immigrants from Asian as well as Central and South American countries entering to the United States during last two decades, intergroup relations involve more than these two groups mentioned above. In some regions, even Hispanic Americans and Asian Americans become majority groups. According to U. S. Citizenship and Immigration Service (2007), approximately $54.6 \%$ of all immigrants in the United States are from Latin America and $26.6 \%$ of the immigrants are from Asian countries. Only recently have more researchers begun to expand racial/ethnic research by including Asian and Hispanic Americans (e.g., Liu, Campbell, \& Condie, 1995; Phinney, Ferguson, \& Tate, 1997; Chen, Edwards,' Young, \& Greenberger, 2001). Therefore, the present study examined the majority group members' acculturation orientations towards two non-dominant groups; Asian and Hispanic immigrant groups. Moreover, in order to examine a more precise interethnic relationship 
between the majority and minority groups, immigrants' specific countries of origin were selected from these two ethnic groups, namely Japanese and Mexican.

As was mentioned previously, the IAM proposes that host majority members' acculturation orientations might differ depending on the valued or devalued status of immigrant groups (Bourhis et al., 1997). According to the social distance study by Owen, Eisner, and McFaul (1981), which investigated Americans' perceptions of closeness towards other ethnic groups, Japanese was found to be the most favorable ethnic group among other Asian ethnic groups. Additionally, Japanese are often perceived as having high levels of education, occupational status (Mar \& Kim, 1994), and economic achievements (Ong \& Hee, 1994), all of which are favorable attributes. In contrast, the U. S. Citizenship and Immigration Service (2007) estimated that approximately 11.3 million illegal immigrants resided in the United States and approximately $57 \%$ of them were from Mexico. The increasing visibility of illegal immigrants over the past years has created public concern about the social and economic impact of immigrants. Furthermore, Americans hold negative stereotypes about Mexican immigrants such as being poor, lazy, dependent on social services, and costly for the states in which they reside, displacing native workers, and driving down wages of comparably skilled native workers (Espanshade \& Calhoun, 1993). In addition, a more recent social distance study showed that Mexicans were the least favorable ethnic group among Latin Americans in the United States (Parrillo \& Donoghue, 2005). Based on these findings, Japanese immigrants are considered as "valued" and Mexican immigrants as "devalued" groups for the present study. Thus, the present study focuses on examining host majority group 
members' acculturation orientations towards Japanese immigrants as a valued group and Mexican immigrants as a devalued group. Based on the past research findings, the following hypothesis was tested.

Hypothesis 1: Integrationism and individualism will be the most endorsed strategies by Euro-Americans towards the valued immigrant group (Japanese immigrants), whereas assimilationism, segregationism, and exclusionism will be the more endorsed orientation styles towards the devalued immigrant group (Mexican immigrants).

Domain Specificity

Researchers have asserted that immigrants might adopt different acculturation strategies, depending on specific life domains (Zane \& Mak, 2003). That is, an acculturating individual's choice of maintaining one's heritage culture and/or assimilating into the host culture might vary across specific situations; the individual might prefer to maintain his/her heritage cultural values at home, while he/she might prefer to assimilate into the host culture at school or work.

Zan and Mark (2003), by content analyzing popular acculturation measures, identified ten distinct life domains (i.e., language use, social affiliation, daily living habits, cultural traditions, communication style, cultural identity/pride, perceived discrimination, general status, family socialization, and cultural knowledge/beliefs/values). Some of these domains could be considered as public domains (e.g., social affiliation), while others could be identified as private domains (e.g., family socialization). It has been asserted that immigrants prefer to maintain their heritage culture in a private domain, 
whereas they prefer to adapt to host culture in a public domain (Clement \& Noels, 1992; Taylor \& Lambert, 1996).

For example, Arends-Toth and Van de Vijver (2004), examining the acculturation orientations of Turkish immigrants and the Dutch native's preferred orientations towards them in the Netherlands, found that Dutch dominant members preferred an assimilation strategy for Turkish immigrants in both public and private domains; however, the Turkish immigrants preferred a separation strategy in a private domain, but an integration strategy in a public domain. For Turkish immigrants, a private domain might be a distinct social life experience which is separated from their public life in the host country. These findings imply that the preference of acculturation strategies might be different across life domains for dominant and non-dominant groups.

In contrast, a study conducted in the United Sates showed different results in which both samples of dominant group members (Caucasian and African American women) and immigrant group members (Cuban, Nicaraguan, and Haitian women) in Miami agreed that it was appropriate for immigrants to maintain their heritage cultures and languages at home, and to adopt mainstream American culture and using English language in a public setting (Taylor \& Lambert, 1996). Even though, these research findings from the Netherlands and the United States seem to be contradictory, there is a consensus with respect to adopting host dominant cultures in a public domain among both dominant and non-dominant group members. More specifically, the dominant group members of these two countries preferred immigrant groups to adopt the dominant 
cultures in a public domain. Considering these results, the following hypothesis was tested.

Hypothesis 2: Euro-American dominant group members will prefer nondominant group members (both Japanese and Mexican immigrants) to adopt an assimilationist strategy in a public domain (i.e., housing and employment) but a segregationist strategy in a private domain (i.e., cultural maintenance and endogamy/exogamy).

\section{Individual Difference Factors}

Another major goal of the present study is to investigate the relationship between individual difference factors and acculturation strategies. Recent empirical research shows that there is a pattern of relationships between individual values and type of acculturation strategies endorsed by dominant group members. For example, Canadian host majority members who endorsed acculturation orientations that were rejecting (i.e., assimilationism, segregationism, and exclusionism) shared a number of psychological characteristics such as possessing authoritarian and ethnocentric ideology, feelings of being threatened by immigrants, and having few friends or contacts with immigrants (Montreuil \& Bourhis, 2004). Is the social psychological profile of each acculturation orientation distinct? The following sections attempt to answer this question by introducing specific psychological variables based on previous empirical research findings and the premise of the IAM. 


\section{Social Dominance Orientation}

Pratto, Sidanius, Stallworth, and Malle (1994) introduced an intergroup relations construct termed social dominance orientation (SDO). According to them, SDO is defined as ""the degree to which a person desires to establish and maintain the superiority of his/her own group over other groups" (p. 742). SDO plays a role as a motivational factor that underpins racial, class, and gender inequalities and also predicts racist and sexist attitudes. Pratto et al. (1994) argue that those who are high on SDO tend to endorse "hierarchy-enhancing" (producing and maintaining higher levels of group-based social inequality) ideologies and policies, whereas those who are low on SDO tend to prefer "hierarchy-attenuating" (producing greater levels of group-based social equality) ideologies and policies. This intergroup attitude might be related to an attitude towards immigrants and immigration. As support of this assertion, SDO had strong and negative associations with attitudes towards immigrants, willingness to empower immigrants, and willingness to provide direct assistance to immigrants (Pratto et al., 1994). In addition, those who were high on SDO were likely to report that immigration decreased the availability of jobs for non-immigrants, indicating perceived competition with immigrants for jobs (Esses et al., 2001).

It can be assumed that intergroup relations attitudes and host majority members' acculturation orientations towards immigrants are related (Zick, Wagner, van Dick, \& Petzel, 2001). Empirical support for such assertion was obtained by Bourhis and Dayan (2004), who found that host majority members low on SDO in Israel were likely to prefer integrationism and individualism over assimilationism, segregationism, and exclusionism, 
whereas those who were high on SDO were likely to endorse assimilationism, segregationism, and exclusionism more than integrationism and individualism. Thus, these findings indicate that those who prefer ethnic inequality within the society are not likely to support multicultural ideology (i.e., not endorsing integration and individualism). The welcoming acculturation attitudes towards immigrants might be related to positive intergroup relational attitudes. Therefore, it is hypothesized that

Hypothesis 3: SDO will be negatively related to integrationism and individualism, and positively related to assimilationism, segregationism, and exclusionism.

\section{Social Distance}

Another important factor that might be related to host majority members' preferred acculturation orientations is the degree to which these individuals are willing to seek contact with members of other ethnic groups (i.e., social distance). Social distance is an individual's degree of desired social intimacy towards outgroups. It has been asserted that the more individuals desire to have contact with members of out-groups, the less likely they are to be prejudiced against the out-groups (Bogardus, 1933). For instance, Southeastern Asian refugees in the United States who desired to have closer contact with Euro-Americans tended to have favorable attributions about EuroAmericans (e.g., friendly, nice, warm), which led to less prejudice attitudes towards Euro-Americans (Lee, Templer, Mar, \& Canfield, 2002).

How are social distance attitudes related to host majority members' acculturation strategies towards different immigrant groups? Bourhis and Dayan (2004) examined host Jewish Israeli's willingness to have close relations with Jewish Russian immigrants, 
Ethiopian immigrants, and Israeli Arabic immigrants. Specifically, they measured the extent to which Jewish Israelis wished to have a person from each of these three minority groups as a clerk, a colleague, a neighbor, and a best friend. Findings showed that host Jewish Israelis who had more desire to have a close relationship with Jewish immigrants tended to endorse individualism and integrationism than those who reported to avoid close relations with them, in which they tended to prefer assimilationism, segregationism, and exclusionism. A similar pattern of results was obtained from a study by Montreuil and Bourhis (2001) in Canada. Therefore, it might be asserted that host majority members' desire to have contact with immigrant groups has a different association with the acculturation strategies.

Hypothesis 4: Social distance will be positively related to integrationism and individualism, but negatively related to assimilationism, segregationism and exclusionism.

Self-efficacy

The other self-concept variable which might be related to majority members' acculturation attitudes towards immigrants is self-efficacy. This concept reflects an individual's confidence concerning his/her abilities to achieve personal goals in social encounters (Bandura, 1986). Individuals who have higher self-efficacy tend to have an openness attitude for contact with outgroups (Allard \& Landry, 1992). There is evidence that shows that majority group members' self-efficacy is related to acculturation orientations towards immigrants. For example, Piontkowski, Florack, Hoelker, and Obdrzalek (2000) examined the relationship between self-efficacy and Slovak (dominant 
group) acculturation attitudes towards Hungarian (non-dominant) group. They found that dominant Slovak individuals who had high self-efficacy tended to endorse integrationism towards non-dominant Hungarians. On the other hand, Slovaks with assimilationist and marginalizationist attitudes reported lower self-efficacy than individuals who endorsed integration and separation strategies. Based on these findings, the following hypothesis is proposed.

Hypothesis 5: Self-efficacy will be positively related to integrationism and individualism, but negatively related to assimilationism, segregationism and exclusionism.

Research question: Which of the individual difference predictors makes the greatest contribution to each of the majority group members' acculturation orientations? 
Method

\section{Participants}

A total of 128 Euro-American college students in Northern California participated in the study. There were 42 males and 86 females. Participants' age ranged from 18 to 51 years, with the mean age of 20.90 years $(S D=5.19)$. Most of the participants $(59.3 \%)$ were $4^{\text {th }}$ generation Americans, followed by $20.3 \%$ 3rd generation, and $8.5 \%$ nd generation, and $5.9 \%$ were $1^{\text {st }}$ generation. The rest of $5.9 \%$ participants stated as other. Immigrants and foreign students were excluded from this study. A total of 107 participants took a paper-and pencil questionnaire and 21 participants took the websurvey.

In this study, all participants were from San Jose State University. This institution is located in the Silicon Valley. There are 24,390 undergraduate and 7,516 graduate students. The average age is 23.5 years old for undergraduate students and 31.3 years old for graduate students. The top five ethnicities of students who attend the university are European American (27\%), Asian American (23\%), Hispanic American (16\%), Filipino (7\%), and African American (5\%), with total of 52\% minority students.

\section{Procedure}

Participants were asked to fill out questionnaires either in a classroom setting or through a web-survey with an encryption system. In the classroom setting, an experimenter informed participants that the study was about examining one's opinion about particular groups of immigrants settled in the United States and about his/her preferred acculturation strategies towards the members of these groups. After this brief 
explanation, participants were asked to complete an informed consent and were then provided with questionnaires which measured acculturation strategies, social dominance orientations, social distance, and self-efficacy. After they completed the questionnaire, participants were provided with a written debriefing, and received course requirement credit. All completed forms were deposited and kept in separate boxes to ensure confidentiality.

Participants who preferred to participate through the online medium contacted the experimenter and acquired the URL for the web-survey. A first page contained a consent form and only participants who agreed to participate in this study proceeded to main survey pages. The entire web-survey generally took approximately 30 minutes to complete. After they completed the survey, they were shown a debriefing page to further understand the purpose of the study.

\section{Measures}

\section{Acculturation Strategies}

Acculturation strategies were measured by using the Host Community Acculturation Scale (HCAS) (Bourhis et al., 1997). The HCAS consist of four life domains: cultural maintenance, endogamy-exogamy, employment, and housing. Each domain contained five items. These five items measured the five acculturative strategies: integrationism, individualism assimilationism, segregationism, and exclusionism. Sample items for the domain of cultural maintenance are: "Mexican immigrants should maintain their own heritage culture while also adopting the American culture" (integrationism), "Whether Mexican immigrants maintain their cultural heritage or adopt 
the American culture makes no difference because each person is free to adopt the culture of his/her choice" (individualism), "Mexican immigrants should give up their culture of origin for the sake of adopting the American culture" (assimilationism), "Mexican immigrants can maintain their culture of origin as long as they do not mix it with American culture" (segregationism), and "Mexican immigrants should not maintain their culture of origin, nor adopt the American culture, because, in any case, there should be less immigration to this country" (exclusionism).

Participants were asked to indicate the degree to which they agreed with each statement on a 7-point Likert-type scale ( $1=$ strongly disagree, $7=$ strongly agree $)$. Participants completed the HCAS twice, one for attitudes towards Mexican immigrants, and another for attitudes towards Japanese immigrants. The coefficient alphas for each acculturation strategy were integrationism (.82), individualism (.74), assimilationism (.83), segregationism (.85), and exclusionism (.84). Items were summed and averaged. Higher scores indicate the more endorsement of a particular acculturation strategy. The items are given in Appendix.

\section{Social Dominance Orientation}

The Social Dominance Orientation Scale (Pratto et al., 1994) was used to measure individuals' desire and support for one's in-group dominance and superiority to outgroups. It consisted of 16 items. A sample item is that "Some groups of people are simply inferior to other groups." Using a 7-point Likert-type scale (1 = strongly disagree, $7=$ strongly agree), participants responded to each statement. Items were summed and 
averaged; the coefficient alpha for this variable was .92. Higher scores indicate more social dominance orientation. The items are given in Appendix.

\section{Social Distance}

Social distance was measured by the 7-item scale developed by Bogardus (1933). All items was measured on a 5-point Likert-type scale $(1=$ strongly disagree, $5=$ strongly agree). Participants were asked to rate how much they desired to have social intimacy with Mexican and Japanese immigrant groups. A sample item is "To a social group as a personal friend." Items were summed and averaged; the coefficient alpha for this variable was .76 for the Mexican immigrant group and .77 for the Japanese immigrant group. Higher scores indicate a more desire for close relationship (i.e., less social distance towards out-groups). The items are given in Appendix.

Self-Efficacy

Self-efficacy was measured by using the General Self-Efficacy Scale (Schwarzer \& Jerusalem, 1995). The scale consists of 10 items and uses a 4 point-Likert-type scale $(1=$ not at all true, $4=$ exactly true $)$. A sample item is that "It is easy for me to stick to my aims and accomplish my goals." Items were summed and averaged; the coefficient alpha was .87. Higher scores indicate more self-efficacy. The items are given in Appendix.

\section{Demographic Information}

Participants were also asked about their age, gender, year in school, and generation status. 
Results

\section{Descriptive Statistics}

Table 1 presents means and standard deviations of the five acculturation strategies as a function of the national origins of the immigrant groups and of life domains. Respondents endorsed integrationism, individualism, and assimilationism similarly to both Japanese and Mexican immigrants, but they endorsed segregationism and exclusionism somewhat more towards Mexican immigrants than Japanese immigrants. Respondents overwhelmingly preferred integrationism and individualism to both immigrant groups. In terms of life domains, respondents endorsed both integrationism and individualism more than the other acculturation strategies both in the private and public domain. However, respondents preferred strongly integrationism, individualism, assimilationism more in the public domain than in the private domain, but they endorsed the segregationism and exclusionism more in the private domain than in the public domain. Respondents seemed least likely to endorse exclusionism in the public domain. 
Table 1

Means and Standard Deviations as a Function of the National Origin of Immigrant Groups and Life Domains

\begin{tabular}{|c|c|c|c|c|c|c|c|c|}
\hline \multirow[t]{2}{*}{ Strategy } & \multicolumn{2}{|c|}{ Mexican } & \multicolumn{2}{|c|}{ Japanese } & \multicolumn{2}{|c|}{ Private } & \multicolumn{2}{|c|}{ Public } \\
\hline & Mean & SD & Mean & $\mathrm{SD}$ & Mean & $\mathrm{SD}$ & Mean & $\mathrm{SD}$ \\
\hline Integrationism & 5.68 & 1.04 & 5.64 & 1.08 & 5.36 & 1.15 & 5.96 & 1.24 \\
\hline Individualism & 5.59 & 1.11 & 5.67 & 1.03 & 5.23 & 1.38 & 6.02 & 1.26 \\
\hline Assimilationism & 2.26 & .99 & 2.26 & 1.14 & 2.04 & 1.07 & 2.48 & 1.33 \\
\hline Segregationism & 2.28 & 1.09 & 2.21 & 1.10 & 2.46 & 1.26 & 2.03 & 1.18 \\
\hline Exclusionism & 1.91 & .93 & 1.84 & .95 & 2.24 & 1.21 & 1.51 & .83 \\
\hline
\end{tabular}


Table 2 displays means, standard deviations, internal consistency reliabilities (Cronbach's $\alpha$ ), and correlations among the overall acculturation orientations and individual difference variables. On the whole, respondents strongly endorsed integrationism $(M=5.66, S D=1.01)$ and individualism $(M=5.63, S D=1.02)$. Assimilation $(M=2.26, S D=1.00)$ and segregationism $(M=2.25, S D=1.06)$ were weakly endorsed. Exclusionism $(M=1.88, S D=.89)$ was the least endorsed acculturation orientation. Intercorrelations among these five acculturation orientations showed a strong positive relationship between integrationism and individualism $(r=.72$, $p<.01$ ). In addition, assimilationism, segregationism, and exclusionism were all strongly correlated with each other. Furthermore, both integrationism and individualism were negatively and significantly correlated with assimilationism, segregationism and exclusionism. These findings were consistent with previous research.

With respect to the individual difference variables, respondents weakly endorsed the social dominance ideology $(M=2.36, S D=1.05)$, that is, the respondents in the present study were likely to prefer greater group equality. Overall, the respondents were highly and equally interested in having relations with both Mexican and Japanese immigrant groups $(M=4.02, S D=.69$ for Mexican immigrants and $M=4.02, S D=.70$ for Japanese immigrants). Respondents on average had a positive self-efficacy $(M=3.30$, $S D=.42)$ 
Table 2

Means, Standard Deviations, Correlations, and Internal Consistency Reliabilities of the Measured Variables

\begin{tabular}{|c|c|c|c|c|c|c|c|c|c|c|c|}
\hline & Variable & Mean & $\mathrm{SD}$ & 1 & & 2 & & 3 & & 4 & \\
\hline 1 & Integrationism & 5.66 & 1.01 & .82 & & & & & & & \\
\hline 2 & Individualism & 5.63 & 1.02 & .72 & ** & .74 & & & & & \\
\hline 3 & Assimilationism & 2.26 & 1.00 & -.56 & $* *$ & -.53 & $* *$ & .83 & & & \\
\hline 4 & Segregationism & 2.25 & 1.06 & -.62 & $* *$ & -.62 & $* *$ & .73 & $* *$ & .85 & \\
\hline 5 & Exclusionism & 1.88 & .89 & -.65 & $* *$ & -.65 & $* *$ & .73 & $* *$ & .83 & ** \\
\hline 6 & SDO & 2.36 & 1.05 & -.45 & $* *$ & -.41 & $* *$ & .59 & $* *$ & .65 & ** \\
\hline \multirow[t]{2}{*}{7} & Social Distance & 4.02 & .69 & .45 & ** & .47 & $* *$ & -.46 & $* *$ & -.57 & ** \\
\hline & (Mexican) & & & & & & & & & & \\
\hline \multirow[t]{2}{*}{8} & Social Distance & 4.02 &. .70 & .41 & $* *$ & .38 & $* *$ & -.41 & $* *$ & -.52 & ** \\
\hline & (Japanese) & & & & & & & & & & \\
\hline 9 & Self-efficacy & 3.30 & .42 & -.15 & $*$ & -.04 & & -.04 & & -.08 & \\
\hline
\end{tabular}

Note. $n=128 ;{ }^{* *} p<0.0 \mathrm{I} .{ }^{*} p<0.05$.

Reliability coefficients presented on the diagonal. 
Table 2 (continued).

Means, Standard Deviations, Correlations, and internal Consistency Reliabilities of the Measured Variables

\begin{tabular}{|c|c|c|c|c|c|c|c|c|c|}
\hline & Variable & 5 & & 6 & & 7 & & 8 & 9 \\
\hline 1 & Integrationism & & & & & & & & \\
\hline 2 & Individualism & & & & & & & & \\
\hline 3 & Assimilationism & & & & & & & & \\
\hline 4 & Segregationism & & & & & & & & \\
\hline 5 & Exclusionism & .84 & & & & & & & \\
\hline 6 & SDO & .57 & ** & .92 & & & & & \\
\hline 7 & Social Distance (Mexican) & -.55 & ** & -.49 & ** & .76 & & & \\
\hline 8 & Social Distance (Japanese) & -.46 & ** & -.49 & ** & .74 & ** & .77 & \\
\hline 9 & Self-efficacy & .07 & & -.10 & & .01 & & -.03 & .87 \\
\hline
\end{tabular}

Note. $n=128 ;{ }^{* *} p<0.01 .{ }^{*} p<0.05$.

Reliability coefficients presented on the diagonal. 


\section{Test of Hypotheses}

Hypothesis 1 stated that integrationism and individualism would be the most endorsed orientations by Euro-American respondents towards valued (Japanese) immigrants, whereas segregationism and exclusionism would be endorsed more towards devalued (Mexican) immigrants. To test this hypothesis, a repeated-measures analysis of variance (ANOVA) was performed for each of the five acculturation orientations. The results showed that there were no significant differences on the endorsement of each of the acculturation orientations between the valued and devalued immigrant groups, integrationism, $F(1,127)=.32, n s$, individualism $F(1,127)=1.80, n s$, assimilationism, $F(1,127)=.00, n s$, segregationism, $F(1,127)=2.16, n s$, and exclusionism, $F(1,127)=$ 2.09, ns. Means are presented in Table 1. Therefore, Hypothesis 1 was not supported.

Because the national origin of the immigrant group did not have any significant effect on the endorsement of the five acculturation orientations, the overall five acculturation orientations were created. Results of a repeated-measures ANOVA revealed significant differences in the endorsement of the five acculturation orientations, $F(4,127)=448.46 p<.001$. Pair-wise comparisons showed that integrationism and individualism were preferred more than assimilationism and segregationism, and exclusionism was the least preferred acculturation orientation (see Table 2 for the means).

Hypothesis 2 stated that Euro-Americans would prefer both immigrant groups to adopt an assimilationism in a public domain (i.e., housing and employment), but a segregationism in a private domain (i.e., cultural maintenance and endogamy/exogamy). Five separate repeated-measures ANOVA were conducted to test the effects of the life 
domain on the endorsement of the acculturation orientation. As expected, EuroAmerican participants showed significant differences in their preference of the acculturation orientations between the two life domains. As can be seen in Table 1, assimilationism was preferred more in the public domain than in the private domain, $F(1$, $127)=14.18, p<.001$, and segregationism was preferred more in the private setting than in the public setting, $F(1,127)=15.55, p<.001$. Furthermore, results showed that integrationism and individualism were preferred more in the public domain than the private domain, $F(1,127)=28.83, p<.001$, and $F(1,127)=28.70, p<.001$, respectively. Exclusionism was preferred more in the private domain than in the public domain, $F(1,127)=60.41, p<.001$. These results clearly support Hypothesis 2 . However a closer look at Table 2 indicates that integrationism and individualism are the most preferred acculturation orientations regardless of the life domains.

Hypotheses 3-6 were tested using a Pearson correlation, which stated that SDO (H3) would be negatively related to integrationism and individualism, and positively related to assimilationism, segregationism, and exclusionism, while social distance $(\mathrm{H} 4)$ and self-efficacy (H5) would be positively related to integrationism and individualism, but negatively related to assimilationism, segregationism, and exclusionism.

Hypothesis 3 was supported. As can be seen in Table 2, SDO was significantly and negatively correlated with integrationism $(r=-.45, p<.01)$ and individualism $(r=-$ $.41, p<.01$ ), which implies that Euro-American students who did not believe in the superiority of one group over others were more likely to prefer integrationism and individualism. On the contrary, positive correlations were observed between SDO and 
assimilationism, segregationism, and exclusionism $(r=.59, p<.01 ; r=.65, p<.01 ; r$ $=.57, p<.01$, respectively). Thus, Euro-American students who preferred group inequality in society were more likely to endorse assimilationism, segregationism, and exclusionism.

Hypothesis 4 was also supported. Results revealed that social distance for both Mexican and Japanese immigrant groups was positively correlated with integrationism and individualism (for Mexican, $r=.55, p<.01 ; r=.47, p<.01$, respectively, for Japanese, $r=.41, p<.01 ; r=.38, p<.01$, respectively). In contrast, strong negative correlations were obtained between social distance for both Mexican and Japanese immigrants and assimilationism, segregationism, and exclusionism and (for Mexican, $r=$ $-.46, p<.01 ; r=-.57, p<.01 ; r=-.55, p<.01$, respectively, for Japanese, $r=-.41 ; p$ $<.01 ; r=-.52, p<.01 ; r=-.46, p<.01$, respectively)

Hypothesis 5 was not supported. As can be seen in Table 2, only integrationism had a significant relationship with self-efficacy $(r=-.15, p<.05)$. However, the direction of the relationship (i.e., negative) was the opposite of the hypothesis, indicating that those who had higher self-efficacy were less likely to endorse integrationism.

\section{Test of Research Question}

The research question was tested using a multiple regression analysis. Recall that the national origin of the immigrant groups did not have any effect on respondents' endorsement of the five acculturation orientations. Therefore, ten separate multiple regression analyses were conducted - five acculturation orientations separated by two life domains (private and public). Table 3 shows the results of the multiple regression 
analyses for the public domain. As can be seen from the table, SDO was the greatest contributor for predicting integrationism $(\beta=-.26, p<.01)$, assimilationism $(\beta=.45, p$ $<.01)$, segregationism $(\beta=.45, p<.01)$ and exclusionism $(\beta=.29, p<.01)$.

Those who were likely to support group inequality were more likely to endorse assimilationism segregationism and exclusionism, and less likely to endorse integrationism in the public domain. However, unlike other acculturation orientations, SDO was not related to individualism. Social distance for Mexican immigrants was also significantly related to exclusionism. Thus, as far as exclusionism is concerned, those who preferred greater group inequality and less desire to have relationship with Mexican immigrants were likely to endorse exclusionism in the public domain. 
Table 3

Summary Statistics for Multiple Regression Analysis on Acculturation Orientations (Public Domain)

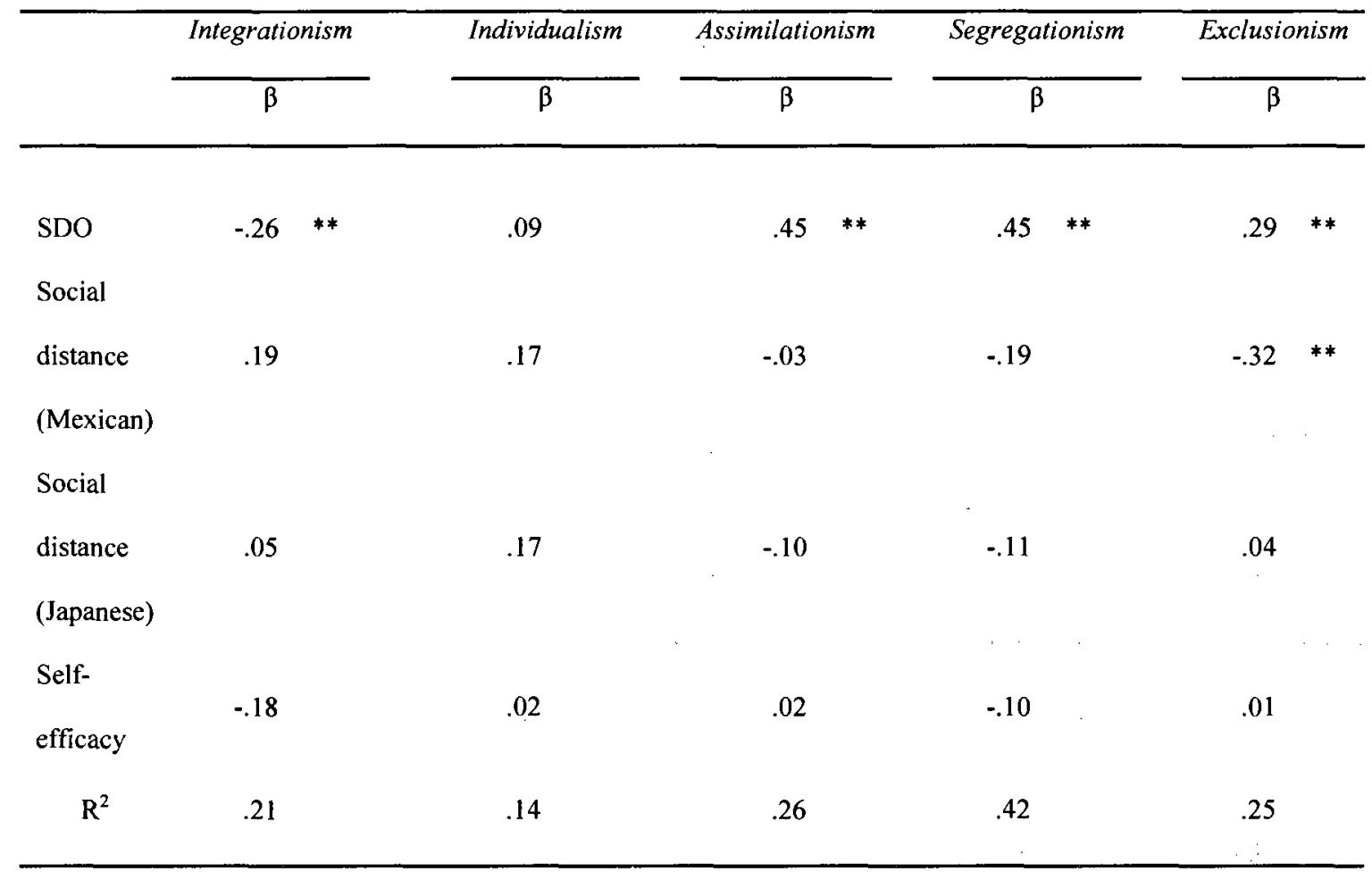

Note. ${ }^{*} p<.05 ;{ }^{*} p<.01$ 
Table 4 shows the results of the multiple regression analyses for the private domain. As can be seen from the table, SDO, social distance for Mexican immigrants, and self-efficacy predicted the integrationist orientation in the private domain. Respondents who endorsed more group equality had a stronger desire to have a close relationship with Mexican immigrants, and those who had lower self-efficacy were more likely to prefer immigrants to adopt integrationism in the private domain. Similarly, SDO and social distance for Mexican immigrants significantly predicted individualism.

As shown in Table 4, SDO and social distance for Mexican immigrants contributed significantly to the prediction of assimilationism, segregationism, and exclusionism in the private domain. Interestingly, respondents who believed in group inequality and sought to avoid close relationships with Mexican immigrants were more likely to endorse these three unwelcome orientations towards immigrants in a private domain. These results show that SDO plays an important role in predicting many of the acculturation strategies in both public and private domains. 
Table 4

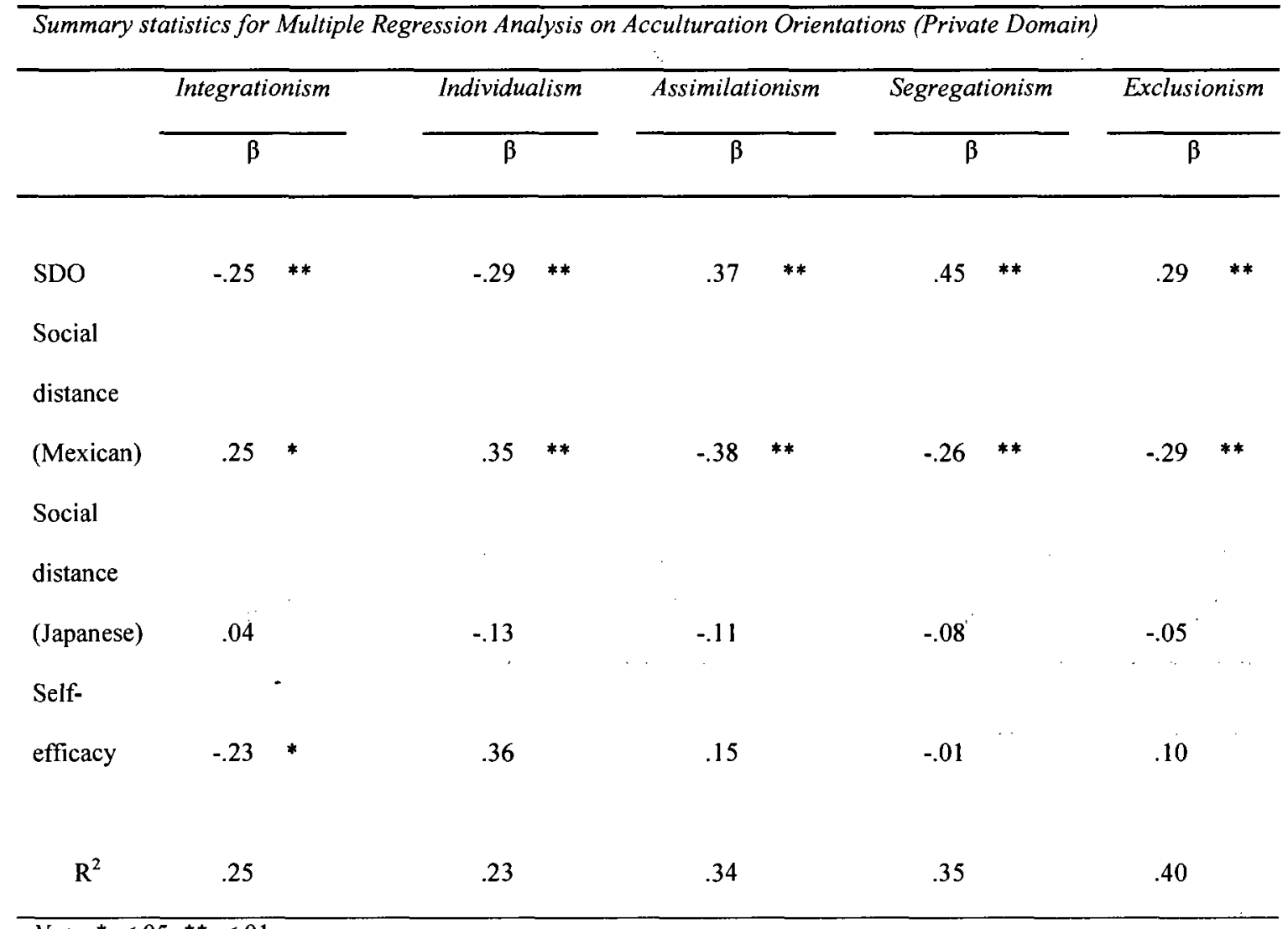

Note. ${ }^{*} p<.05 ;{ }^{* *} p<.01$ 


\section{Discussion}

The present study examined host majority group members' (i.e., Euro-Americans) acculturation orientations towards Mexican and Japanese immigrant groups. Although most researchers have mainly focused on studying immigrants' acculturation strategies, the present study is important given that majority group members' attitudes towards immigrants have great impact on how the immigrants react and acculturate to the dominant society. Specifically, this study investigated Euro-Americans' expectations about how Mexican and Japanese immigrants should adopt to American culture in different life domains, and how individual different factors (SDO, social distance, and self-efficacy) would be related to their acculturation attitudes.

Overall, findings showed that integrationism and individualism were the most preferred acculturation orientations endorsed by Euro-Americans towards both immigrant groups for both life domains. In contrast, exclusionism was the least preferred acculturation orientation followed by segregationism. These findings are consistent with previous research using the IAM (e.g., Barrette et al., 2004; Bourhis \& Dayan, 2004; Montreuil \& Bourhis, 2004; Montreuil \& Bourhis, 2001). This suggests that EuroAmericans are accepting both immigrant group members mostly as individuals regardless of their national origins as well as believing a notion that immigrants should have freedom to maintain their heritage culture as well as adopt the feature of mainstream American culture.

The IAM proposed that the acculturation orientations endorsed by host majority group members might differ as a function of an immigrant group's country of origin. 
This hypothesis was not supported, that is, the target group's country of origin (either Mexican or Japanese) did not have a significant effect on the acculturation orientations endorsed by host majority group members. As will be discussed later, these findings might be due to the fact that participants did not perceive Mexican immigrants as a devalued immigrant group and Japanese immigrants as a valued immigrant group. Furthermore, the United States is an individualistic country (Triandis, 1995); thus, participants preferred the individualistic orientation to perceiving them as members of different ethnic groups.

It was also hypothesized that Euro-Americans would prefer immigrants to adopt the assimilationist strategy in a public domain; but the segregationist strategy in a private domain. Consistent with the hypothesis, Euro-Americans preferred both groups of immigrants to adopt mainstream American culture in the public domain (i.e., housing and work), but preferred them to maintain their own heritage culture in the private domain (i.e., personal cultural beliefs and marriage). These findings are consistent with a study where dominant group members in Miami reported that it was appropriate for immigrant groups (Cuban, Nicaraguan, and Haitian women) to maintain their heritage culture at home, but speak English in public (Taylor \& Lambert, 1996). These findings suggest that host majority members might expect immigrants to behave similar to them in public domains while they are willing to let immigrants maintain their heritage cultural values in private settings. Thus, these findings may reflect the policy of multiculturalism by respecting their heritage culture and letting them adopt American culture; however; it depends on whether majority group members have to be involved with it or not (private 
or public). Interestingly, although much acculturation research showed a clear distinction in the endorsement of acculturation strategies between private and public domains, the present study still showed that integrationism and individualism were the most preferred orientations in both life domains.

The present study also found that integrationism and individualism were highly related to each other, whereas assimilationism, segregationism, and exclusionism were all strongly related to each other. These findings suggest that dominant group members' acculturation orientations might be a single continuum, one end as being welcoming attitudes (i.e., integrationism and individualism) and the other end being unwelcoming attitudes (i.e., assimilationism, segregationism, and exclusionism). Moreover, integrationism and individualism orientations were found to share some common correlates, whereas assimilation, segregation, and exclusion were also found to share similar correlates among them. That is, Euro-Americans who preferred group equality and desired to have a close relationship with Mexican immigrants were likely to endorse integrationism and individualism. In contrast, those who believed in a hierarchical structure within the society and showed reluctance to have a close relationship with Mexican immigrant group members were likely to endorse assimilationism, segregationism, and exclusionism. These findings are consistent with the results obtained by Montreuil and Bourhis (2001) who found that Francophones who preferred greater group inequality and avoided closer relationships with immigrants were likely to have rejecting attitudes towards them. 
When all the individual difference predictors (SDO, social distance, and selfefficacy) were considered simultaneously, SDO exerted stronger predictive power, followed by social distance for Mexican immigrants. In the public domain, SDO was the only significant variable that predicted integrationism, assimilationism, segregationism, and exclusionism. Social distance for Mexican immigrants also predicted exclusionism. None of the individual difference variables contributed to the prediction of individualism. In the private domains, both SDO and social distance for Mexican immigrants significantly contributed to the predictions of all of the acculturation orientations.

Clearly people's beliefs on inequality among social groups and their desire to have close relationships with immigrant group members play significant roles in predicting types of acculturation strategies endorsed by majority group members, especially in the private domain. These results are consistent with previous findings, in which SDO (Pratto, Sidamius, Stallworth, \& Malle, 1994) and social distance (Curseu, Stoop, \& Schalk, 2006) are robust predictors of group prejudice, which in turn are the main antecedents of discrimination. These results indicate the importance of SDO and social distance in immigration and immigrant research.

The results of the present study also suggest that intergroup relation variables (i.e., SDO and social distance) seem to be more important than personality traits. However, an unexpected but interesting finding was the negative relationship between self-efficacy and integrationism. Euro-Americans who had a weaker sense of beliefs about their capabilities were likely to endorse integrationism in a private setting. A potential explanation for this finding is that Euro-Americans who had lower self-efficacy might 
find similarity between themselves and immigrants because immigrants are seen as having lower prestige and status in general (Berry, 2001). Perceived similarity of others to self leads to positive behaviors towards those who are perceived similar and plays an important role in empathy (Batson, Sager, Garst Kang, Rubchinsky, \& Dawson, 1997). Therefore, Euro-Americans who had lower self-efficacy had a welcoming attitude towards immigrants. However, this interpretation is speculative, since there was no empirical research which had discovered the explanation of a direct relationship between self-efficacy and attitudes towards immigrants. Moreover, such finding was true only in private domains, that is, Euro-Americans with lower self-efficacy preferred immigrants to endorse integrationism only in cultural maintenance and marriage, not workplace or school settings. The lack of the negative relationship between self-efficacy and integrationism in the public domain (i.e., workplace or school) could be due to an effect of perceived economic threats, since people who have lower self-efficacy feel a greater economic threat that immigrants are taking employment opportunities away from them (Courtemanche, 2008).

\section{Implications of the Present Study}

The empirical results presented here have implications, especially for managers, as well as inter-group relations trainers in diverse workplaces. As the number of immigrant employees and expatriates increase in the workplace, it is critical for managers and trainers to try to understand immigrant employees' cultures, to educate these employees about dominant culture and values, and to direct ethnic majority employees' attention towards understanding immigrant cultures. 
The findings of the present study may help intergroup relation trainers to develop cultural competency programs and interventions to address acculturation issues and help manage immigrants' acculturative stress. Acculturative stress refers to the "psychocultural stress due to cultural differences found between a host culture and an incoming culture marked by reduction in the physical and mental health status of individuals or groups undergoing acculturation" (Nwadiora \& McAdoo, 1996, P. 477). The results of the present study showed that Euro-Americans preferred both immigrants to endorse the assimilation strategy more in a public domain than in a private domain. Nevertheless, if immigrants would not like to adhere to mainstream American culture in public domains (e.g., workplace, school), they are more likely to face acculturative stress. Acculturative stress is related to having lowered mental health status (e.g., confusion, anxiety, depression), feelings of marginality and alienation, heightened psychosomatic symptom level, and identity confusion (Berry \& Annis, 1974). In addition, Tatar and Horenczyk (2003) found that ethnic majority teachers who preferred assimilationism experienced more burnout symptoms compared with those who preferred integrationism. This study showed that acculturation orientations may not only affect the well-being of ethnic minority employees but also of ethnic majority employees. Moreover, IAM states that ideal immigrant and majority groups' relational outcomes occur when the profile of acculturation orientations for the two groups matches integrationism, individualism, or assimilationism (Bourhis et al., 1997). Furthermore, empirical research has shown that integrationism is the most successful acculturation orientation in terms of an individual's well-being (Berry, 1997) and work-related well-being (e.g., more job satisfaction, more 
organizational commitment, less cynicism) (Peeters \& Oerlemans, 2009). Therefore, it is critical for trainers to educate ethnic majority group employees and immigrant employees on the knowledge of cultural beliefs and values of both cultures.

Putting the results into practice, and considering that majority group members prefer immigrants to endorse assimilationism more in public, hiring managers should adopt different selection criteria when they employ immigrants for jobs. For example, a minimum requirement in the selection process might be that applicants possess at least a business level of reading, writing and speaking English and an individualistic communication strategy if the organizational climate is more in line with mainstream American ideology. Research also indicates that host majority group members would be pleased if the immigrants in their host country voluntarily adopted the language, cultural values and mores of their new society, dedicating effort and energy to integration (Van Oudenhoven et al., 1998).

The culture competency program and immigrant specific selection criteria are effective only when cultural differences are valued, appreciated, and used for organizational and personal gain (Ely \& Thomas, 2001). Organizations should recognize the importance of integrationism and individualism at the workplace as these have a strong relationship with intergroup relational variables. Diverse workplaces are better equipped to work effectively and address changing markets. Focusing on only one mainstream culture where there is one people, one culture, and one nation will eventually absorb the benefit of cultural diversity. Knowing that Euro-Americans prefer a 
multicultural ideology (i.e., integrationism and individualism), it is not impossible to change a mainstream unitary organizational culture into a multicultural one.

\section{Limitations and Directions for Future Research}

Despite the contributions of the present study, it is not without limitations. First, according to Berry (1990), majority group members' preferences for acculturation orientations towards immigrants are often influenced by geographic locations. While most studies were conducted in urban or suburban areas, the present study was conducted in the San Francisco Bay Area, one of the most multiethnic regions in the United States (Isbister, 1996). The area is also well known for its tolerance towards immigrants and gays/lesbians as well as for progressive political activism (Pratt \& Lemieux, 2001). Furthermore, the data were collected from a university with a culturally diverse student body where there were only $28 \%$ Euro-American students. College students have been reported to be more liberal and tolerant towards outgroups than the general population (Berry, 1977). Therefore, the predominant preference of integrationism and individualism endorsed by these Euro-American students might reflect such a geographical influence, students' liberal attitudes towards immigrant groups, or the

combination of both. Nonetheless, it is important to conduct studies in different regions and using different samples such as adults from different socioeconomic backgrounds, occupational statuses, educational backgrounds, and political affiliations in order to further understand majority group members' acculturation orientations towards immigrants. 
Second, the IAM was mainly described as a model for the majority group in the present study; however, it is not limited to the majority group. The model also focuses on investigating the acculturation strategies adopted by immigrants in the host community and the relational outcomes that are the product of both immigrant and majority groups' acculturation orientations. Therefore, the model suggests that the combinations of majority group members' acculturation orientations towards immigrants and immigrants' acculturation strategies could produce consensual, problematic, or conflicting relational outcomes between two groups (Bourhis et al., 1997). According to Bourhis et al. (1997), consensual relations occur when both majority and immigrant group members share either the integrationism, assimilationism, or individualism orientations. Problematic relations emerge when the majority and immigrant group members experience both partial agreement and partial disagreement in terms of their acculturation orientations. For example, a problematic relation results when immigrant group members prefer assimilation while majority group members prefer immigrants to adopt integrationism, and conversely, when immigrant group members prefer integrationism, but majority group members insist that immigrants assimilate to the host mainstream culture. A conflictual relation is produced when majority and immigrant group members endorse segregationism, and exclusionism; thus, both group members are likely to experience a tense relationship with each other because of miscommunication with outgroups and negative stereotypes towards immigrants. Bourhis et al. (1997) have argued that the larger the differences between the attitudes of majority group members and those of immigrants, the more conflicting their relationship will be. Relational outcomes include 
patterns of communications between majority and immigrant groups, interethnic attitudes and stereotypes, acculturative stress, and discrimination towards each other (Bourhis et al., 1997). Therefore, future research should examine the concordance and discordance of the majority members' preferences of the acculturation strategies and immigrants' adoption of the acculturation strategies simultaneously.

Third, the lack of differences in the endorsement of the acculturation orientations for two immigrant groups might be due to the fact that the participants did not view Mexican immigrants as "devalued" and Japanese immigrants as "valued" immigrant groups. Because the present study did not directly ask them whether they perceived Mexican immigrants as a devalued, and Japanese immigrants as a valued immigrant group, the participants might not have perceived these two immigrant groups as separate, but rather they might have viewed these two groups as immigrant groups in general. Therefore, future research should select valued and devalued groups based on results of a pilot study where participants are directly asked to evaluate different immigrant groups.

Alternatively, some might argue that the lack of differences in majority group members' acculturation orientations based on the national origin of the immigrant groups is due to the fact that participants have responded in a socially desirable manner. Although it is possible, such an explanation is unlikely given that the majority of the previous studies conducted a within-subjects design and found differences in acculturation orientations as a function of valued and devalued status of immigrant groups. Nonetheless, future research should consider a between-subjects design; that is, 
presenting only one targeted immigrant group to each participant so that a comparison effect would be diminished.

Fourth, in the present study, only Mexicans and Japanese were selected as target groups to be considered. A study by Berry and Kalin (1995) showed that dominant group members' attitudes towards ethnic groups follow a hierarchy, where some ethnic groups are preferred over others. Future studies should focus on examining majority group members' attitude towards other immigrant groups to further increase the generalizability of the study.

Lastly, the results of the present study show that intergroup relations variables (e.g., SDO, social distance) predicted the acculturation orientations better than an individual difference variable (i.e., self-efficacy). These intergroup relations' variables are often related to prejudice towards ethnic minority members (Pratto et al., 1994). Therefore, other intergroup relations variables (e.g., perceived realistic threat, perceived symbolic threat) that have been related to prejudicial attitudes might better predict the acculturation orientations endorsed by majority group members. Likewise, personality traits such as authoritarianism and ethnocentrism that are related to prejudicial attitudes might be related to the acculturation orientations. Future studies should examine the relationship between these variables and the majority group's acculturation attitudes towards immigrants.

\section{Conclusion}

The present study was conducted in order to understand the acculturation orientations that Euro-Americans would prefer Mexican and Japanese immigrants adopt 
when they immigrate in the United States. Results showed that Euro-Americans preferred both groups of immigrants to adopt integrationism and individualism in both public and private domains. However, they preferred assimilationism more in public domains and segregationism more in private domains. SDO and social distance were also found to predict types of acculturation strategies. Findings of the present study raise more questions than answers. Much research in this topic is needed for evolving everchanging multiethnic societies. 


\section{References}

Abizadeh, A. (2001). Ethnicity, Race, and a Possible Humanity. World Order 33, 23-34.

Allard, R., \& Landry, R. (1992). Ethnolinguistic vitality beliefs and language maintenance and loss. In W. Fase, K. Jaspaert \& S. Kroon (Eds.) Maintenance and loss of minority languages (pp. 171-195). Amsterdam, Philadelphia : J. Benjamins,

Arends-Toth, J., \& Van de Vijver, F. J. R. (2004). Domains and dimensions in acculturation: Implicit theories of Turkish-Dutch. International Journal of Intercultural Relations, 28, 19-35.

Arends-Toth, J., \& Van de Vijver, F. J. R. (2003). Multiculturalism and acculturation: Views of Dutch and Turkish-Dutch. European Journal of Social Psychology, 33, 249-266.

Barrette, G., Bourhis, R. Y., Personnaz, M., \& Personnaz, B. (2004). Acculturation orientations of French and North African undergraduates in Paris. International Journal of Intercultural Relations, 28, 415-438.

Bandura, A. (1986). Fearful expectations and avoidant actions as coeffects of perceived self-inefficacy. American Psychologist, 41, 1389-1391.

Batson, C.D., Sager, K., Garst, E., Kang, M., Rubchinsky, K., \& Dawson, K. (1997). Is empathy-induced helping due to self-other merger? Journal of Personality and Social Psychology, 73, 495-509.

Berry, J. W. (1990). Psychology of acculturation. In J. J. Berman (Ed.), Nebraska Symposium on Motivation, 1989: Cross-cultural perspectives (pp. 201-234). Lincoln, NE: University of Nebraska Press

Berry, J. W. (1997). Immigrations, acculturation and adaptation. Applied Psychology, 46, 5-68.

Berry, J. W. (2001). A psychology of immigration. Journal of Social Issues, 57, 61 5-631.

Berry, J. W. (2003). Conceptual approaches to acculturation. In K. M. Chun, P. B. Organista \& G. Marin (Eds.), Acculturation: Advances in theory, measurement, and applied research (pp. 17-37). Washington, DC: American Psychological Association.

Berry, J. W., \& Kalin, R. (1995). Multicultural and ethnic attitudes in Canada: An overview of the 1991 national survey. Canadian Journal of Behavioral Science, 27, 301-320. 
Berry, J. W., Kalin, R., \& Taylor, D. (1977). Multiculturalism and ethnic attitudes in Canada. Ottawa: Supply \& Services.

Berry, J. W., Kim, U., \& Boski, P. (1988). Psychological acculturation of immigrants. In Y. Y. Kim \& W. B. Gudykunst (Eds.), Cross-cultural adaptation: Current approaches (pp. 62-89). Newbury Park, CA: Sage.

Berry, J. W., \& Krishnan, A. (1992). Acculturative stress and acculturation attitudes among Indian immigrants to the United States. Psychology and Developing Societies, 4, 187-212.

Berry, J. W., Kim, U., Power, S., Young, M. \& Bujaki, M. (1989). Acculturation attitudes in plural societies. Applied Psychology: An International Review, 38, 185-206.

Bogardus, E. S. (1933). A social distance scale. Sociology \& Social Research, 17, 265271.

Bourhis, R. Y., Moise, L. C., Perreault, S., \& Senecal, S. (1997). Towards an interactive acculturation model: A social psychological approach. International Journal of Psychology, 32, 369-386.

Bourhis, R. Y., \& Montreuil, A. (2002). Some methodological issues related to the Host Community Acculturation Scales (HCAS). Working paper.

Bourhis, R. Y., \& Dayan, J. (2004). Acculturation orientations towards Israeli Arabs and Jewish immigrants in Israel. International Journal of Psychology, 39, 118-131.

Chen, C., Edwards, K., Young, B., \& Greenberger, E. (2001). Close relationships between Asian Americans and European American college students. The Journal of Social Psychology, 14, 85-100.

Clement, R. \& Noels, K. A. (1992). Towards a situated approach to ethnolinguistic identity: The effects of status on individuals and groups. Journal of Language and Social Psychology, 11, 203-232.

Courtemanche, M. (2008 July 9). The Effects of Identity and Self-Interest on Support for Immigration Policy Paper presented at the annual meeting of the ISPP 31 st Annual Scientific Meeting, Sciences Po, Paris, France. Retrieved July 23, 2009 from http://www.allacademic.com/meta/p256983_index.html

Dona, G, \& Berry, J. W. (1994). Acculturation attitudes and acculturative stress of Central American refugees. International Journal of Psychology, 29, 57-70. 
Doyle, A., Beaudet, J., \& Aboud, F. E. (1998). Developmental patterns in the flexibility of children's ethnic attitudes. Journal of Cross-Cultural Psychology, 19, 3-18.

DuBors, D. L, \& Hirsch, B. J. (1990). School and neighborhood friendship pattern of Blacks and Whites in early adolescence. Child Development, 61, 524-536.

Ely, R. J., \& Thomas, D. A. (2001). Cultural diversity at work: The effects of diversity perspectives on work group processes and outcomes. Administrative Science Quarterly, 46, 229-273.

Espanshade, T. J., \& Calhoun, C. A. (1993). An analysis of public opinion towards undocumented migration. Population Research and Policy Review, 12, 189-224.

Esses, V.M., Dovidio, J. F., Jackson, L. M. \& Armstrong, T. L. (2001). The immigration dilemma: The role of perceived group competition, ethnic prejudice and national identity. Journal of Social Issues, 57, 389-412.

Graves, T. (1967). Psychological acculturation in a tri-ethnic community. Southwestern Journal of Anthropology, 23, 337-350.

Isbister, J. (1996). The immigration debate: Remaking America. West Hartford, CT: Kumarian.

LaFromboise, T, Soleman, H. L. K., \& Gerton, J. (1993). Psychological impact of biculturalism. Evidence and theory. Psychological Bulletin, 114, 395-412.

Lee, S.Q., Templer, D. I., Mar, J., \& Canfield, M. (2002). Social distance and trait attribution among four Southeast Asian ethnic groups in the United States. Psychological Reports, 91, 326-330.

Liu, J. H., Campbell, S. M., \& Condie, H. (1995). Ethnocentrism in dating preferences for an American sample: The ingroup bias in social context. European Journal of Social Psychology, 25, 95-115.

Mar, D., \& Kim, M. (1994). Historical trends In P Ong (Ed), The state of Asian Pacific America: Economic diversity, issues, and policies (pp 13-30). Los Angeles Leadership Education for Asian Pacific (LEAP) and UCLA Asian American Studies Center.

Montreuil, A., \& Bourhis, R. Y. (2001). Majority acculturation orientations towards "valued" and "devalued" immigrants. Journal of Cross-Cultural Psychology, 32, 698-719. 
Montreuil, A., \& Bourhis, R. Y. (2004). Acculturation orientation of competing host communities towards valued and devalued immigrants. International Journal of Intercultural Relations, 28, 507-532.

Navas, M., Garcia, M. C., Sanchez, J., Rojas, A. J., Pumares, P., \& Fernandez, J. S. (2005). Relative acculturation extended model (RAEM): New contributions with regard to the study of acculturation. International Journal of Intercultural Relations, 29, 21-37.

Nwadiora, E., \& McAdoo, H. (1996). Acculturative stress among American refugees: Gender and racial differences. Adolescence, 31, 477-487.

Owen, C., Eisner, H. C., \& McFaul, T. (1981). A Half-Century of Social Distance Research: National Replication of the Bogardus Studies. Sociology and Social Research, 66, 80-98.

Padilla, A. M., \& Perez, W. (2003). Acculturation, social identity, and social cognition: A new perspective. Hispanic Journal of Behavioral Sciences, 25, 35-55.

Parrillo, V. N., \& Donoghue, C. (2005). Updating the Bogardus social distance studies: A new national survey. The Social Science Journal, 42, 257-271.

Peeters, M, W., \& Oerlemans, W.M. (2009). The relationship between acculturation orientations and work-related well-being: Differences between ethnic minority and majority employees. International Journal of Stress Management, 16, 1-24.

Phinney, J. S., Ferguson, D. L., \& Tate, J. D. (1997). Intergroup attitudes among ethnic minority adolescents: A causal model. Child Development, 68, 955-969.

Piontkowski, U., Florack, A., Hoelker, P., \& Obdrzalek, P. (2000). Predicting acculturation attitudes of dominant and non-dominant groups. International Journal of Intercultural Relations, 24, 1-26.

Pratto, F., Sidamius, J., Stallworth, L. M., \& Malle, B. F. (1994). Social dominance orientation: A personality variable predicting social and political attitudes. Journal of Personality and Social Psychology, 67, 741-763,

Redfield, R., Linton, R., \& Herskovits, M. J. (1936). Memorandum for the study of acculturation. American Anthropologist, 38, 149-152. 
Rudmin, F. W., \& Ahmadzadeh, V. (2001). Psychometric critique of acculturation psychology: The case of Iranian migrants in Norway. Scandinavian Journal of Psychology, 42, 41-56.

Padilla, A. M., \& Perez, W. (2003). Acculturation, social identity, and social cognition: A new perspective. Hispanic Journal of Behavioral Science, 25, 35-55.

Sayegh, L., \& Lasry, J. C. (1993). Immigrants' adaptation in Canada: Assimilation acculturation, and orthogonal cultural identification. Canadian Psychology, 34, 98-109.

Schwarzer, R., \& Jerusalem, M. (1995). Generalized self-efficacy scale. In J. Weinman, S. Wright, \& M. Johnston (Eds.), Measures in health psychology: A user's portfolio. Causal and control beliefs (pp. 35-37). Windsor, UK: NFER-NELSON.

Stephan, W. G., Ybarra, O., \& Bachman, G. (1999). Prejudice towards immigrants. Journal of Applied Social Psychology, 29, 2221-2237.

Steffensmeier, D. \& Ulmer, J. T. (2006). Black and White Control of Numbers Gambling: A Cultural Assets-Social Capital View. American Sociological Review, $71,123-156$.

Tatar, M., \& Horenczyk, G. (2003). Diversity-related burnout among teachers. Teaching and Teacher Education, 19, 397-408.

Tchoryk-Pelletier, P. (1989). L'adaptation des minorities ethniques [The adaptation of ethnic minorities]. Montreal: Cegep de St-Laurent.

Taylor, D. M., \& Lambert, W. E. (1996). The meaning of multiculturalism in a culturally diverse urban American area. Journal of Social Psychology, 136, 727-740.

Triandis, C. H. (1995). Individualism \& Collectivism. Boulder, CO: Westview Press.

U. S. Citizenship and Immigration Service. (n.d.). 2007 Immigration and naturalization. Retrieved March 3, 2009. from http://www.uscis.gov

Van Oudenhoven, J. P., Prins, K. S., \& Buunk, B. P. (1998). Attitudes of minority and majority members towards adaptation of immigrants. European Journal of Social Psychology, 28, 995-1013.

Zane, N., \& Mak, W. (2003). Major approaches to the measurement of acculturation among ethnic minority populations: A content analysis and an alternative empirical strategy. In K. M. Chun, P. B. Organista \& G. Marin (Eds.), Acculturation: Advances in theory, measurement and applied research (pp. 3960). Washington, DC: American Psychological Association. 
Zick, A., Wagner, U., Van Dick, R., \& Petzel, T. (2001). Acculturation and prejudice in Germany: Majority and minority perspectives. Journal of Social Issues, 57, 541557. 


\section{Appendix A}

Survey Items

Acculturation strategies towards Mexican immigrants (Bourhis et al., 1997)

1. Mexican immigrants should maintain their own heritage culture while also adopting the dominant American culture.

2. Whether Mexican immigrants maintain their cultural heritage or adopt the dominant American culture makes no difference because each person is free to adopt the culture of his/her choice.

3. Mexican immigrants should give up their culture of origin for the sake of adopting the dominant American culture.

4. Mexican immigrants can maintain their culture of origin as long as they do not mix it with the dominant American culture.

5. Mexican immigrants should not maintain their culture of origin, nor adopt the dominant American culture, because, in any case, there should be less immigration to this country.

6. I would be as likely to marry a Mexican person as I would an American person because marriage between two people should not be influenced by the cultural origin of the spouses.

7. I would be as likely to marry a Mexican person as I would an American person, as long as the culture of both spouses was respected.

8. I would marry a Mexican person as long as he/she would give up his/her culture of origin for the sake of adopting mainstream American culture.

9. I would prefer to marry an American person rather than a Mexican person because it is better not to mix culture.

10. I would refuse to marry a Mexican person because it is important to maintain the strength of mainstream American culture.

11. When a job is available, employers should always refuse to hire Mexican candidates.

12. When a job is available, employers should hire Mexican candidates only if the latter conform to the work habits of dominant Americans.

13. When a job is available, only the individual merits of the candidate should be considered, whether the candidate is Mexican or American.

14. When a job is available, employers should be as likely to hire a Mexican as an American candidate, and this, regardless of the cultural habits of Mexicans.

15. Certain job domains should be reserved only for American candidates while other job domains should be reserved strictly for Mexican candidates.

16. When an apartment is available for rent, the apartment managers should always refuse to rent to Mexicans.

17. When an apartment is available, apartment managers should rent to Mexicans only if they conform to living arrangements and practices of dominant Americans. 
18. When an apartment if available, only the requirements of the apartment community should be considered when choosing a tenant, whether they are Mexicans or Americans.

19. When an apartment is available, apartment managers should be as likely to rent to Mexicans as Americans, no matter what the cultural habits of the prospective tenant.

20. Certain areas and apartments should be reserved for Americans, while other rental areas should be reserved for Mexicans.

Acculturation strategies towards Japanese immigrants (Bourhis et al., 1997)

1. Japanese immigrants should maintain their own heritage culture while also adopting the dominant American culture.

2. Whether Japanese immigrants maintain their cultural heritage or adopt the dominant American culture makes no difference because each person is free to adopt the culture of his/her choice.

3. Japanese immigrants should give up their culture of origin for the sake of adopting the dominant American culture.

4. Japanese immigrants can maintain their culture of origin as long as they do not mix it with the dominant American culture.

5. Japanese immigrants should not maintain their culture of origin, nor adopt the dominant American culture, because, in any case, there should be less immigration to this country.

6. I would be as likely to marry a Japanese person as I would an American person because marriage between two people should not be influenced by the cultural origin of the spouses.

7. I would be as likely to marry a Japanese person as I would an American person, as long as the culture of both spouses was respected.

8. I would marry a Japanese person as long as he/she would give up his/her culture of origin for the sake of adopting mainstream American culture.

9. I would prefer to marry an American person rather than a Japanese person because it is better not to mix culture.

10. I would refuse to marry a Japanese person because it is important to maintain the strength of mainstream American culture.

11. When a job is available, employers should always refuse to hire Japanese candidates.

12. When a job is available, employers should hire Japanese candidates only if the latter conform to the work habits of dominant Americans.

13. When a job is available, only the individual merits of the candidate should be considered, whether the candidate is Japanese or American.

14. When a job is available, employers should be as likely to hire a Japanese candidate as an American candidate, and this, regardless of the cultural habits of Japanese.

15. Certain job domains should be reserved only for American candidates while other job domains should be reserved strictly for Japanese candidates.

16. When an apartment is available for rent, the apartment managers should always refuse to rent to Japanese. 
17. When an apartment is available, apartment managers should rent to Japanese only if they conform to living arrangements and practices of dominant Americans.

18. When an apartment if available, only the requirements of the apartment community should be considered when choosing a tenant, whether they are Japanese or Americans.

19. When an apartment is available, apartment managers should be as likely to rent to Japanese as Americans, no matter what the cultural habits of the prospective tenant.

20. Certain areas and apartments should be reserved for Americans, while other rental areas should be reserved for Japanese.

Social dominance orientation (Pratto et al., 1994)

1. Some groups of people are simply inferior to other groups.

2. In getting what you want, it is sometimes necessary to use force against other groups.

3. It's OK if some groups have more of a chance in life than others.

4. To get ahead in life it is sometimes necessary to step on others.

5. If certain group stayed in their place, we would have fewer problems.

6. It's probably a good thing that certain groups are at the top and other groups are at the bottom.

7. Inferior groups should stay in their place.

8. Sometimes other groups must be kept in their place.

9. It would be good if groups could be equal.

10. Group equality should be our ideal.

11. All groups should be given an equal chance in life.

12. We should do what we can to equalize conditions for different groups.

13. Increased social equality.

14. We should have fewer problems if we treated people more equally.

15. We should strive to make incomes as equal as possible.

16. No one group should dominate in society.

Social distance (Bogardus, 1933)

1. To close kinship by marriage.

2. To a social group as a personal friend.

3. To my street as neighbors.

4. To employment in my workplace.

5. To citizenship in my country.

6. As visitors only to my country.

7. Would exclude from my country.

Self-efficacy (Schwarzer \& Jerusalem, 1995)

1. I can always manage to solve difficult problems if I try hard enough.

2. If someone opposes me, I can find the means and ways to get what I want. 
3. It is easy for me to stick to my aims and accomplish my goals.

4. I am confident that I could deal efficiently with unexpected events.

5. Thanks to my resourcefulness, I know how to handle unforeseen situations.

6. I can solve most problems if I invest the necessary effort.

7. I can remain calm when facing difficulties because I can rely on my coping abilities.

8. When I am confronted with a problem, I can usually find several solutions.

9. If I am in trouble, I can usually think of a solution.

10 . I can usually handle whatever comes my way. 